
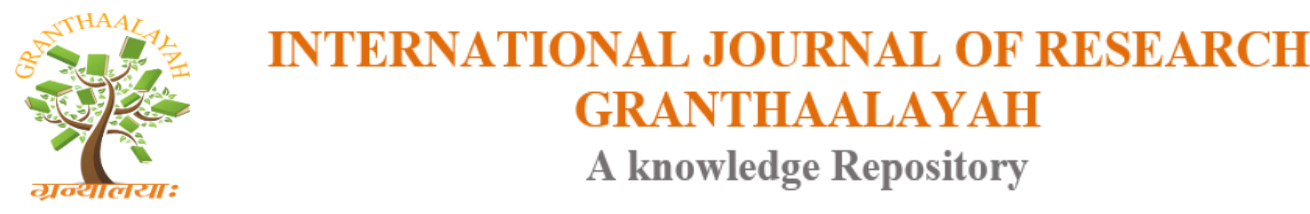

Science

\title{
REMOTE SENSING AND GIS IN URBAN SPRAWL AND ARABLE LAND LOSS ANALYSIS: A CASE OF BAMAKO DISTRICT IN MALI
}

\author{
Ruan Renzong *1, An Ru ${ }^{2}$, Moussa Aliou Keita ${ }^{3}$ \\ ${ }^{* 1,2,3}$ School of the Earth Sciences and Engineering, Hohai University, China
}

\begin{abstract}
This paper analyzes the impacts of urban sprawl on arable land loss in Bamako district from 1990 to 2018 by using remote sensing and geographic information science capabilities. The analysis was based on satellite images classification of Landsat Thematic Mapper (TM) 1990, 2000, Landsat Enhanced Thematic Mapper Plus (ETM+) 2010, Landsat 8 Operational Land Image and Thermal Infrared Sensor (OLI/TIRS) image for 2018 to show land use and cover changes, in particular arable land loss. The results showed a significant evolution of land use and land cover and important arable land loss. From 1990 to 2018, the construction has increased by $73.06 \%$ while arable land decreased by $55.39 \%$. The results also revealed that urban sprawl has exceeded the administrative boundaries of Bamako and is continuing in neighboring municipalities. This article recommends the adoption of legal measures, the development of urban development master plan, and close collaboration with different actors involve in land management for better management of arable land and urban sprawl. Finally, for a global understanding of the phenomenon in the urban area of Bamako, the study suggests a more in-depth study of a global approach to urban sprawl in the Bamako district, taking into account the surrounding rural communes, which affect today greatly the urban sprawl of Bamako.
\end{abstract}

Keywords: Arable Land; Built-Up; Geographic Information System; Remote Sensing; Urban Sprawl; Water.

Cite This Article: Ruan Renzong, An Ru, and Moussa Aliou Keita. (2018). "REMOTE SENSING AND GIS IN URBAN SPRAWL AND ARABLE LAND LOSS ANALYSIS: A CASE OF BAMAKO DISTRICT IN MALI." International Journal of Research - Granthaalayah, 6(8), 1-15. https://doi.org/10.29121/granthaalayah.v6.i8.2018.1256.

\section{Introduction}

Urban sprawl has become one of the growing research issues in the present development scenario, where population growth and migration for better livelihoods have paved the way for rapid urban expansion [1]. A simplistic explanation, urban sprawl is referred as the expansion of urban concentration beyond its initial limits. However different definitions of urban sprawl exist according to schools. Although a precise definition of urban sprawl is discussed, a general consensus is that urban sprawl is characterized by unplanned and uneven use and an increase in 
the built-up area along the urban and rural fringe or may be defined as a peripheral growth with an unlimited and non-contiguous path to the outside of the solid core of a metropolitan area [2]. Sprawl features on spatial configuration: fragmentation and irregularity of land use patches are strong evidence for discontinuous, strip and leapfrog development, and noticeable planning inconsistency [3].

For a past few decades, cities in developing countries have been growing in terms of urbanization supported by strong population growth and a massive immigration for various reasons [4]. This new urban logic generates multidimensional implications at ecological, socio-economic, health and environmental levels; in particular arable land loss [5]. The management of these problems is a challenge for developing world and their urban authorities that are often in a situation of financial, material and strategic helplessness to cope with them [7]. Urban growth in Bamako is currently reflecting this scenario of sudden and abrupt expansion.

Being country capital, Bamako is the centre of economical and industrial development as well as famous for job creation, wealth and better living conditions, that's why, it remains the main pole of attraction for the rural exodus, which contributes greatly to population growth [8].

The spatial patterns of urban growth can be categorized into three types: special objectivesoriented type, social-political intervention type, and normal urban growth type. The major factors influencing urban expansion and land use/cover change are also important. In general, the population, traffic conditions, industrialization, and policies are the major factors that have influenced the urban expansion [9]. These driving forces, including planning policy, population size and composition, transformation of the industrial structure and economic growth of the development zone are the main reasons for urban sprawl [10]. For Mediterranean regions such as Athens, it has been found that urban competitiveness among many others would be one of the fundamental reasons for urban attraction and growth or urban sprawl. The 'urban competitiveness' discussion inquiries into the ability of metropolitan areas to attract investment, addressing also the socio-economic implications of the re-orientation of planning goals in this direction [11]. Urban sprawl has been largely driven by demographic change, social and economic development, and the transition in land use regulation [12]. The exceptional growth of many urban agglomerations in many developing countries is the result of a three-fold process of structural change: the transition of agricultural employment, strong population growth and increased urbanization rates [13]. Looking at the example of the United States, urban expansion has occurred in a perfect market economic system. However, urban sprawl in many cities of China has emerged during a transition period of the Chinese economy from a planned economic system to an economic market system [14]. High rates of urbanization, which is monumental, resulted in an increased population that has outgrown the management capabilities of cities in the developing world. The existing formal planning standards and tenure regulations have proven inappropriate to meet these challenges in most of the cases. Informal urbanization is by-passing formal planning regulations and creating parallel structures in order to tackle their existent problems [15].

Presently, in the regions of Kayes, Koulikoro, Sikasso, Segou, Mopti and around the district of Bamako, there is a massive continuing conversion of prime agricultural lands to housing, commercial establishments, and industrial estates. Solely based on the land cover changes around 
Bamako the expansion of urban area rose from $41.72 \mathrm{~km} 2$ in 1986 to $102.48 \mathrm{~km} 2$ in 2006 . The increase rate was $72 \%$ per year, and the average rate was 5.62 [16].

Studies of land cover and land use changes have been conducted by researchers as a key to understand global environmental change, and even global warming which is very often a condition for land use $[17,18]$. According to the pace and scale of urban expansion in many parts of the globe, urban environments are playing an increasingly important role in daily quality of life issues, ecological processes, climate, material flows, and land transformations [19].

As a first consequence of the dual pressure of urbanization and rapid population growth, the loss of arable land in and around Bamako district was one of the major manifestations of urban growth during last few decades. Therefore, this article aims to analyze the relationship between urban sprawl and arable land loss in Bamako district in recent decades by relying on the capabilities of remote sensing and geographic information systems. This is to draw the consequences and make proposals for solutions to attract the attention of decision-makers towards the challenges in controlling the urban sprawl and arable land loss.

This study is presented and discussed in four sections: the first section provides an overview of current knowledge on urban growth and sprawl as a whole. In the next section, the materials and methods are presented: it presents the study area, the remote sensing data and the software used, and the methodology of data processing. The third section discusses significant results and discussions. The last section draws conclusions and suggestions.

\section{Materials and Methodology}

\subsection{Study Area}

The study area Bamako located in the south-west part of the country is the capital of the Republic of Mali. Bamako district is further subdivided into six municipalities (Fig. 1: map of Bamako and its six municipalities) and is located in southern Mali (Fig. 2: The map of Mali and Bamako location). The maximum area of Bamako is $267 \mathrm{sq} \mathrm{km}$ with 3,337,122 inhabitants and a population density of 1115 inhabitants per sq $\mathrm{km}$, according to the last census (source: Bamako district municipality, 2016). It is located at $7^{\circ} 59^{\prime}$ 'west longitude and $12^{\circ} 40^{\prime}$ north latitude on both banks of the Niger River, Bamako district is divided into two parts. The North Shore built between the Niger River and Mount Manding in the alluvial plains meeting at both ends East and West. In the south shore a site of more than 12,000 ha is area of the Senou airport and reliefs from Tienkoulou to the Niger River.

For its geological formations and soils, the district of Bamako rests on a granite basement gneissic and schistous covered with sandstone sediment. The river has cut deeper and deeper into the shales and granitoids of the basement and the sedimentary cover. Its allusions occupy the major bed of the river while the recent deposits fill the depression of the riverbed after each flood. There are two types of superficial formations: soils resulting from alteration and lateralization of rock, and alluvial formations occupying the major and minor beds of the river as well as its tributaries. Geographically located in the North-Sudanese zone, the dry season lasts from November to April and the winter season dominate from May to October. The rainfall can vary between 750 to 1400 
$\mathrm{mm}$. Rainfall also varies from $0 \mathrm{~mm}$ in the driest months (January, February) to 290 min the most rainy month (August) with $290 \mathrm{~min}$. The variation in temperatures throughout the year is $6.7^{\circ} \mathrm{C}$. In May, the average temperature is $31.5{ }^{\circ} \mathrm{C}$ therefore the hottest month of the year. The vegetal formations of Bamako district are the savannah and the gallery forests punctuating the rivers.

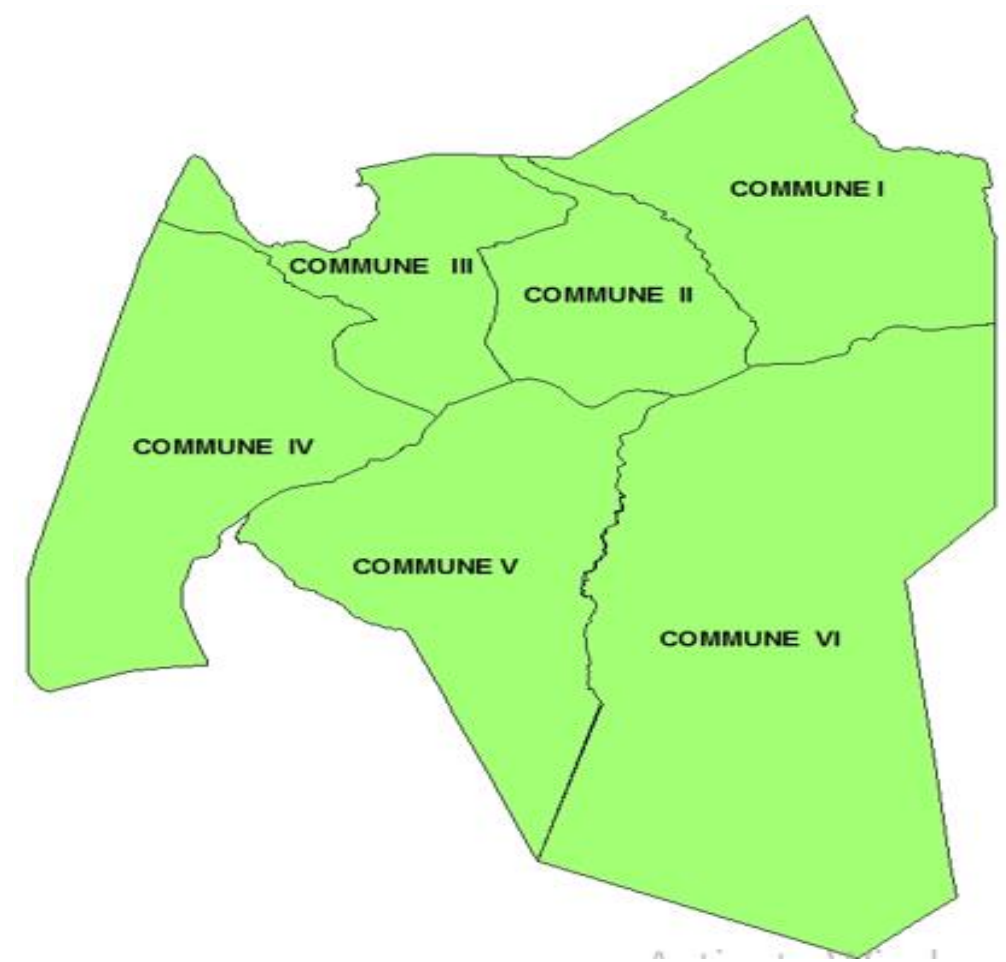

Figure 1: The Bamako district and its municipalities

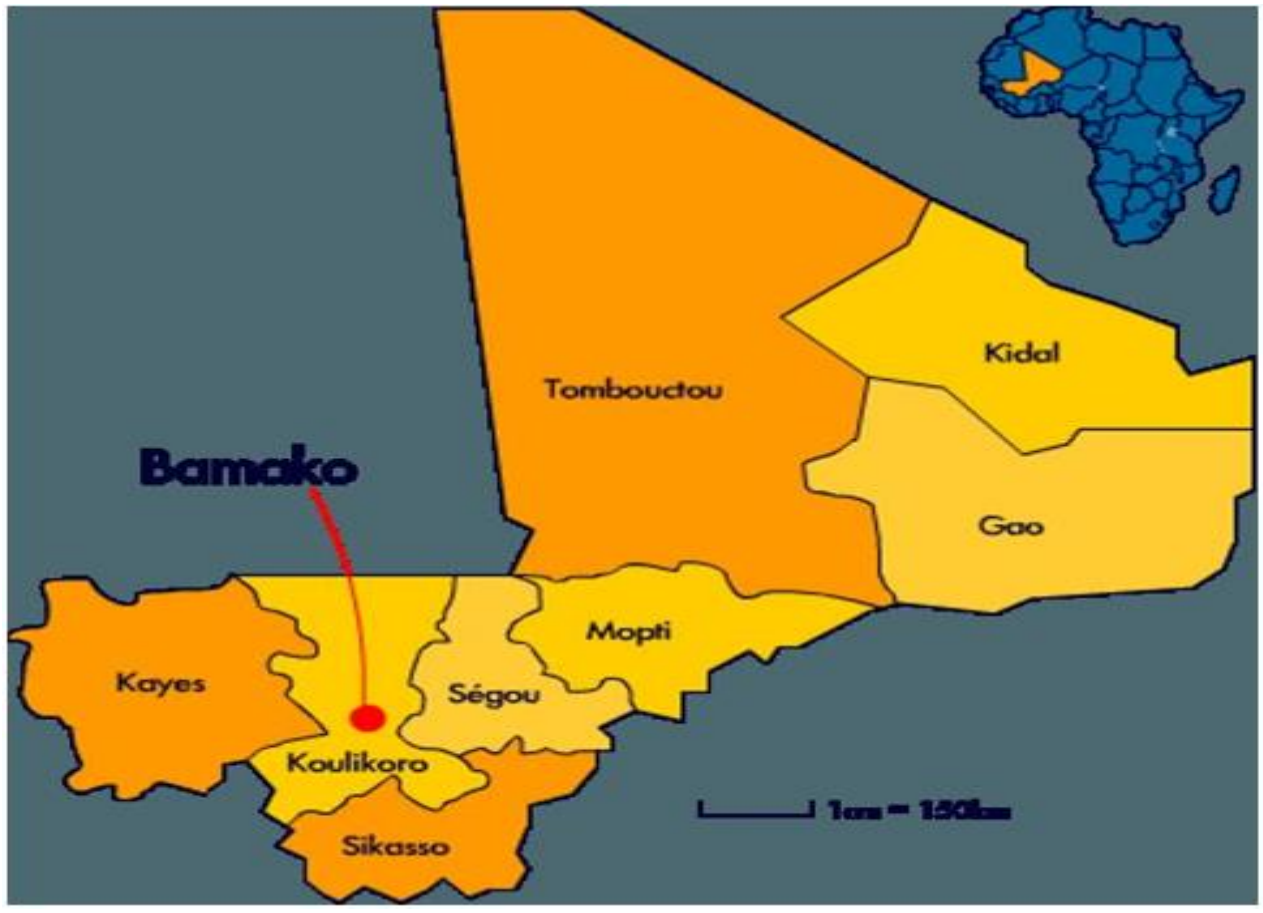

Figure 2: Mali administrative map and Bamako location 


\subsection{Data and Materials}

For this study, four data Landsat images for the years 1990, 2000, 2010 and 2018 were downloaded free of charge by Earth Explorer. The characteristics on these images are shown in Table 1. Bamako shape file was used as secondary data to extract from satellite images study area boundaries. The remote sensing software eCognition Developer 8.7, ENVI 5.2, and the Geographical Information System software Arc GIS 10.2 were used for further data analysis.

Table1: The characteristics of images data

\begin{tabular}{|l|c|c|c|c|c|c|c|}
\hline Landsat & Path & Row & Sensor & $\begin{array}{c}\text { Spatial } \\
\text { Resolution }\end{array}$ & $\begin{array}{c}\text { Bands } \\
\text { number }\end{array}$ & $\begin{array}{c}\text { Radiometric } \\
\text { resolution }\end{array}$ & $\begin{array}{c}\text { Acquisition } \\
\text { date }\end{array}$ \\
\hline Landsat 5 & 199 & 51 & TM & $30 \mathrm{~m}$ & 7 & $8 \mathrm{bits}$ & $11 / 12 / 1990$ \\
\hline Landsat 5 & 199 & 51 & TM & $30 \mathrm{~m}$ & 7 & $8 \mathrm{bits}$ & $30 / 12 / 2000$ \\
\hline Landsat 7 & 199 & 51 & ETM + & $30 \mathrm{~m}$ & 7 & $8 \mathrm{bits}$ & $02 / 12 / 2010$ \\
\hline Landsat 8 & 199 & 51 & OLI-TIRS & $30 \mathrm{~m}$ & 11 & $16 \mathrm{bits}$ & $06 / 01 / 2018$ \\
\hline
\end{tabular}

OLI-TIRS: Operation Land Imager- Thermal Infrared Sensor; TM: Thematic Mapper; ETM+: Enhance Thematic Mapper Plus

\section{Methodology}

The three-step mechanism was adopted for data interpretation: Firstly, the data was selected and image data was downloaded, then pre-processing of data was performed, finally segmentation and classification, and post-classification operations were exhibited.

\subsection{Pre-Processing}

For pre-processing of each image, using ENVI 5.2, layers stacking was done before radiometric calibration which comprised of normalization of the signals in order to make a multi-temporal analysis and to compare the images. It was followed by atmospheric correction in order to reduce the effects of atmospheric variables (the amount of water vapour, the distribution of aerosols ...) on the electromagnetic radiation. For atmospheric correction, the FLAASH module (Fast Line-ofsight Atmospheric Analysis of Hypercubes) was used. FLAASH module is the main tool for atmospheric correction of multispectral and hyperspectral images that operate in the wavelength range from visible to infrared (above $3 \mu \mathrm{m}$ ). Finally, the study area boundaries were extracted from the processed images of Bamako shape file in ArcGIS by clip method.

\subsection{Segmentation and Classification}

The clip images were downloaded into eCognition software, and RGB colour composite in falsecolour (bands 4,3,2 for TM and ETM+; and bands 5,4,3 for OLI-TIRS) had been applied to improve the quality of the spectral and geographical characteristics of the entities on the images to facilitate their identification, segmentation and classification. These bands were chosen on the basis of the spectral properties which show high reflectance of green vegetation as these were chlorophyll absorbing bands [20]. Specifically, bands 2 and 3 were used because these produced distinct spectral signatures for vegetation which was needed for analysis. Band 4 was a near infrared band which showed contrast between vegetation and soil while band 5 which was a mid- 
infrared band helped to differentiate between vegetation and built up/bare areas for easy image classification [5].

Multi-resolution segmentation algorithm was used for images segmentation. It was based on principal of gradual merging of regions around their starting points according to a user-defined homogeneity criterion. The parameter values used for segmentation are shown in Table 2.

The segmented images were further classified under the same eCognition Developer 8.7 software using the object-oriented classification approach. This object-oriented approach is based on the assumption that the semantic information necessary for the interpretation of an image is not represented in the individual pixels, but in significant objects and their mutual relations [21]. The advantage of this approach is consideration of the spectral and spatial characteristics of the pixel and its neighborhood in the classification process [22]. That's why the nearest neighbor classification method based on predefined class samples was used in this study. Three classes have been created using class hierarchy window: arable land, built-up and water. Arable include: soils, vegetation, mountains, farm land and so on. Built-up include: housings, economics zones, industrial zones, transportation network and facilities etc. Water is the river Niger. Samples based created classes object features were selected on segmented images, and after this nearest neighbor classification method was applied to classify images. Classified images were exported as a shape in Arc Map for post-classification processing.

Table 2: The parameter values of segmentation algorithm

\begin{tabular}{|c|c|c|c|c|}
\hline Images & Scale parameters & Shape & Compactness & level \\
\hline Landsat TM & 20 & 0.3 & 0.8 & 1 \\
\hline Landsat TM & 20 & 0.3 & 0.8 & 1 \\
\hline Landsat ETM + & 20 & 0.3 & 0.8 & 1 \\
\hline Landsat OLI-TIRS & 20 & 0.5 & 0.5 & 1 \\
\hline
\end{tabular}

\subsection{Post-Classification}

Post-classification step has concerned firstly to organize a new classification in Arc Map using symbology classification based on created classes that has been done after dissolving classes. Secondly, the classification accuracy assessment was performed by creating random samples using Arc toolbox data management tools and then exported the random samples as shape file. These random samples were further projected on the basis of satellite image and the classified images in order to verify the reliability of the results of the classification by using the selected location. Classification accuracy assessment statistics such as producer accuracy, user accuracy, overall accuracy, and Kappa coefficient are shown in the confusion matrix in Table 3. It gives descriptive and analytical statistics on the reliability of the classification. Traditionally, the total number of correct pixels in a category is divided by the total number of pixels of that category as derived from the reference data (i.e. column total). This accuracy measure indicates the probability of a reference pixel being correctly classified and is really a measure of omission error. This accuracy measure is called producer's accuracy simply because the producer of the classification is interested in how well a certain area can be classified [23]. On the other hand, if the total number of correct pixels in a category is divided by the total number of pixels that were classified in that category, then this result is a measure of commission error. This measure, called user's accuracy 
or reliability, is indicative of the probability that a pixel classified on the map or image actually represents that category on the ground [24]. Overall accuracy gives an idea of the accuracy of classified images. Thirdly, maps of urban sprawl and arable land loss were processed for each study years.

Table 3 : Confusion matrix of classification accuracy assessment

\begin{tabular}{|c|c|c|c|c|c|}
\hline & Arable land & Built-up & Water & Total & User' accuracy \\
\hline Arable land & $\mathbf{3 3}$ & 1 & 2 & 36 & $91.66 \%$ \\
\hline Built-up & 8 & $\mathbf{1 1 7}$ & 0 & 125 & $93.60 \%$ \\
\hline Water & 0 & 0 & $\mathbf{1 1}$ & 11 & $100 \%$ \\
\hline Total & 41 & 118 & 13 & $\mathbf{1 7 2}$ & \\
\hline Producer'saccuracy & $80.74 \%$ & $99.15 \%$ & 84.61 & & \\
\hline
\end{tabular}

Overall accuracy : 93.98\% Kappa coefficient : 0.888

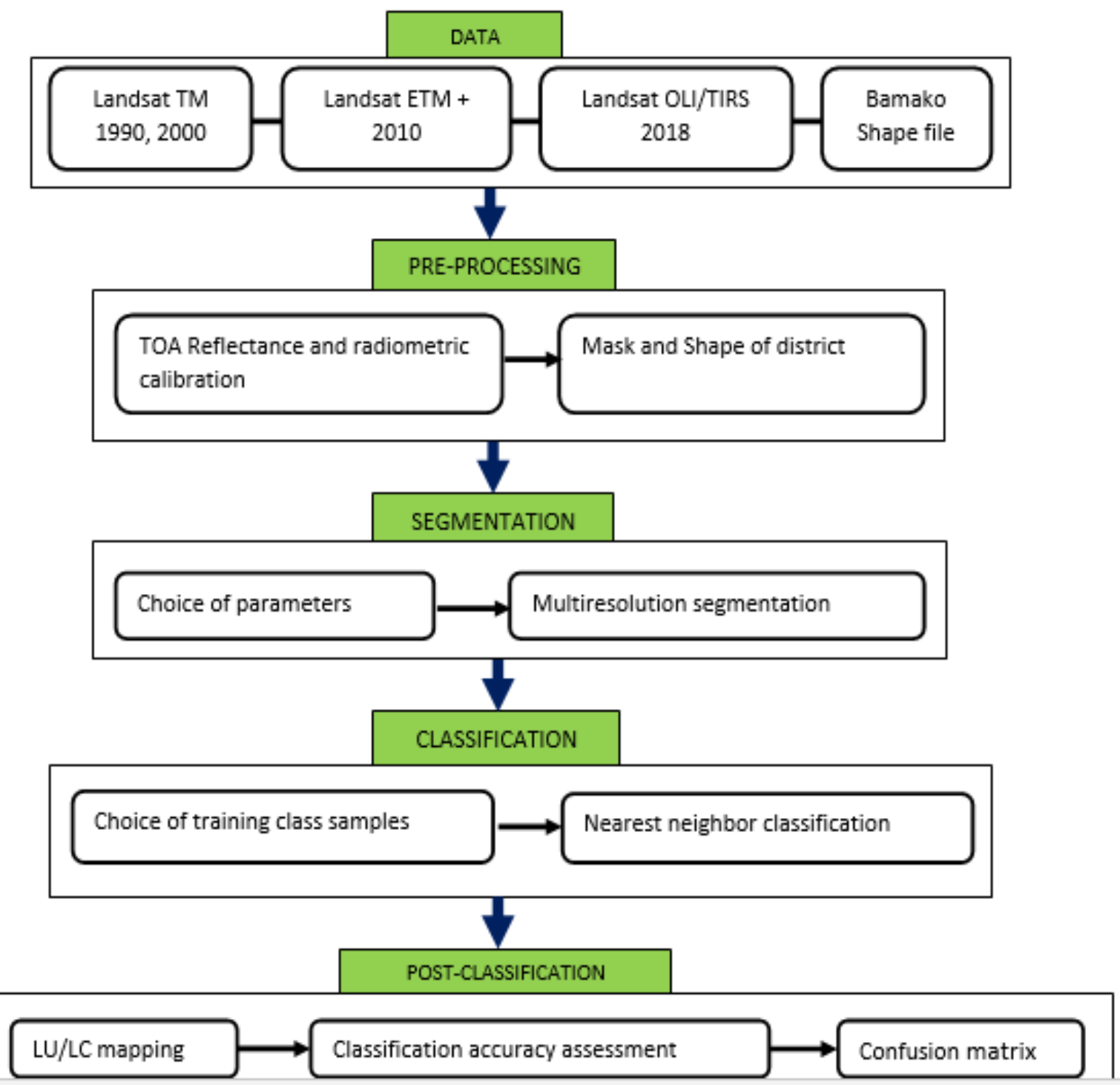

Figure 3: illustrates the methodology flowchart applied in this study. 


\section{Results and Discussions}

\subsection{Results}

Exploiting the capabilities of remote sensing and geographic information systems is a valuable mean of analyzing urban sprawl and arable land loss in time and space. These tools used in this study enabled a judicious analysis and follow-up of the urban sprawl and arable land loss in Bamako from 1990 to 2018. The results from satellite image processing of 1990, 2000, 2010 and 2018 as well as statistics computed automatically using the Arc GIS software amply demonstrate the importance of urban sprawl phenomena and arable land loss in the district of Bamako. For the District of Bamako, a hundred hectoris illegally urbanized annually. This spatial display of the city as reflected by densities is in no urban at all (40\% against 100 to 200). Same situation exists in other capitals of the country denoting an absence of land control [25]. The statistics on the evolution of buildings and arable land are presented in Table 4, shows clearly the loss of arable land as a consequence of sprawl, like the other cities in the world where urban sprawl remains the main factor responsible for the loss of arable land. One of the harmful consequences of periurbanization is the utilization of agricultural land for urban uses, which is imposing socioeconomic consequences for peasants that are dispossessed of their land. The rapid conversions of arable lands to urban use means that rural farmers would have limited access to land, and natural capital for their livelihood activities. The rural inhabitants, particularly farmers who have been deprived of their land or whose tenure security is at risk and has minute commodity to sell, are the most vulnerable to such transformations [26]

The ratio statistics, considering the year 1990 as the baseline, are perfect illustrations of the extent of sprawl and arable land loss. For urban sprawl, the ratios have evolved from $17.71 \%$ in 2000, $61.52 \%$ in 2010 , to $73.06 \%$ in 2018 . This means sprawl of built-up area was $17.71 \%$ between 1990 and $2000,61.52 \%$ from 1990 to 2010, and $73.06 \%$ from 1990 to 2018. For arable land the ratios are: $-12.62 \%$ in $2000,-46.49 \%$ in $2010,-55.39 \%$ in 2018 . This depicts a decrease in arable land: $12.62 \%$ from 1990 to $2000,-46.49 \%$ from 1990 to $2010,-55.39 \%$ from 1990 to 2018 . It was noted that the period marked by greater growth of buildings and loss of arable land was 2000 to 2010 . In order to understand the changes in land-use and occupancy square meter area statistics is presented in Table 4.

The maps in Figure 4 show that the spread from 1990 to 2000 was significant towards the interstices where most was reserved for green spaces, urban agricultural spaces, and sports spaces. From 2000 to 2018, the sprawl of the city was in horizontal spaces, sports spaces. Moreover, it was in the form of horizontal strip on both banks of the river between the mountains which was extended from north to North West on the left bank of the river and the airport zone to the south. An important point to make here is that urban sprawl in Bamako district has exceeded the administrative limits of the district and continue in neighboring peri-urban rural municipalities. Fig. 5 shows the spread of the district of Bamako in its suburban municipalities. The pressure on these spaces creates land conflicts among the occupants of these spaces, the administrative or municipal authorities and private owners, following the sale of the land. Land disputes linked to administrative boundaries for land property controls opposing two municipalities or two neighboring communities. It should also be emphasized here that more land disputes are brought 
to the justice/court of large cities in Mali than many other conflicts, particularly in Bamako and surrounding areas following urban growth and uncontrolled land management.

Presently in Bamako, urban congestion and air pollution are also one of the consequences of urban sprawl supported by population growth as well as domestic combustion, industries and the very rapid increase in the number of vehicles meeting the needs of urban areas over long distances created by urban sprawl. Congestion in many large cities can also be extremely severe and air pollution is now a serious environmental concern in many cities [4].

Studies also show that spontaneous habitat greatly contributed to the urban sprawl of Bamako before and during our study period. The spontaneous habitat was built on the outskirts of the city. "A spontaneous neighborhood is a neighborhood that has anarchically pushed under the effect of urban growth, outside areas officially attributed to housing uses. It is a neighborhood with no legal status, no legal plan of subdivision, whose occupation is illegal, according to the legislation in force. It is also a district generally inhabited by a layer of population composed of rural inhabitants recently arrived in town or old urban people that are unable to support the conditions of the city center. It is also most often a neighborhood almost devoid of equipment [25].

Table 4: Built-up and arable land change statistics taking 1990 as baseline

\begin{tabular}{|l|l|l|l|l|}
\hline Years & Built-up per sq m & Ratio\% & Arable land per sq m & Ratio\% \\
\hline 1990 & 96895521 & & 126988931 & \\
\hline 2000 & 114059137 & 17.71 & 110921962 & -12.62 \\
\hline 2010 & 156507750 & 61.52 & 67947300 & -46.49 \\
\hline 2018 & 167693850 & 73.06 & 56648925 & -55.39 \\
\hline
\end{tabular}

\section{Bamako Urban Sprawl and Arable Land Lost Maps}

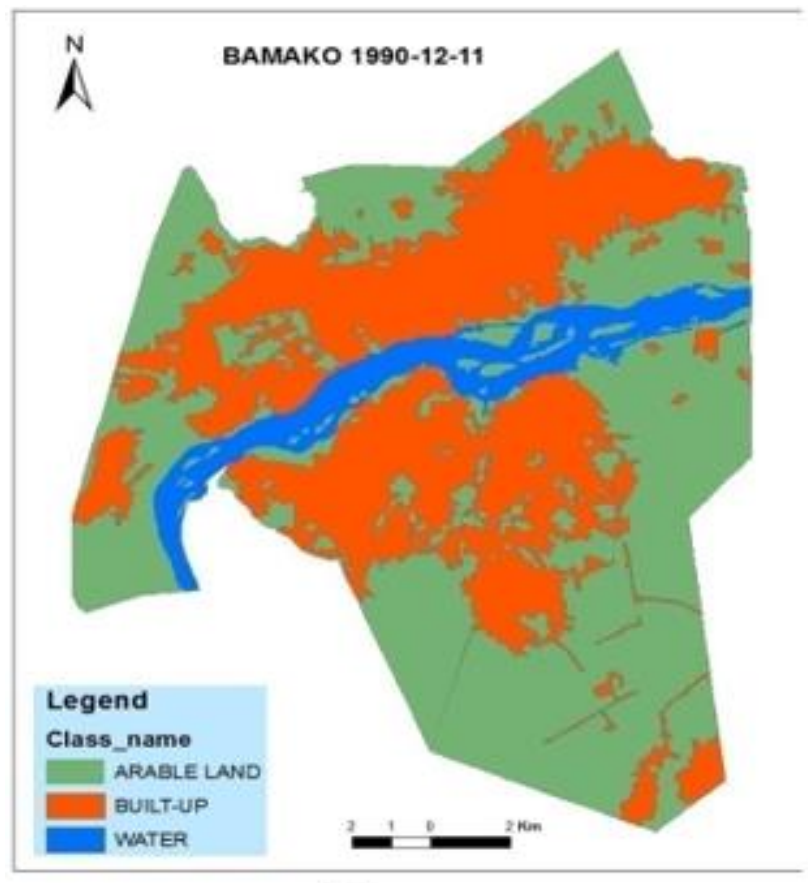

(a)

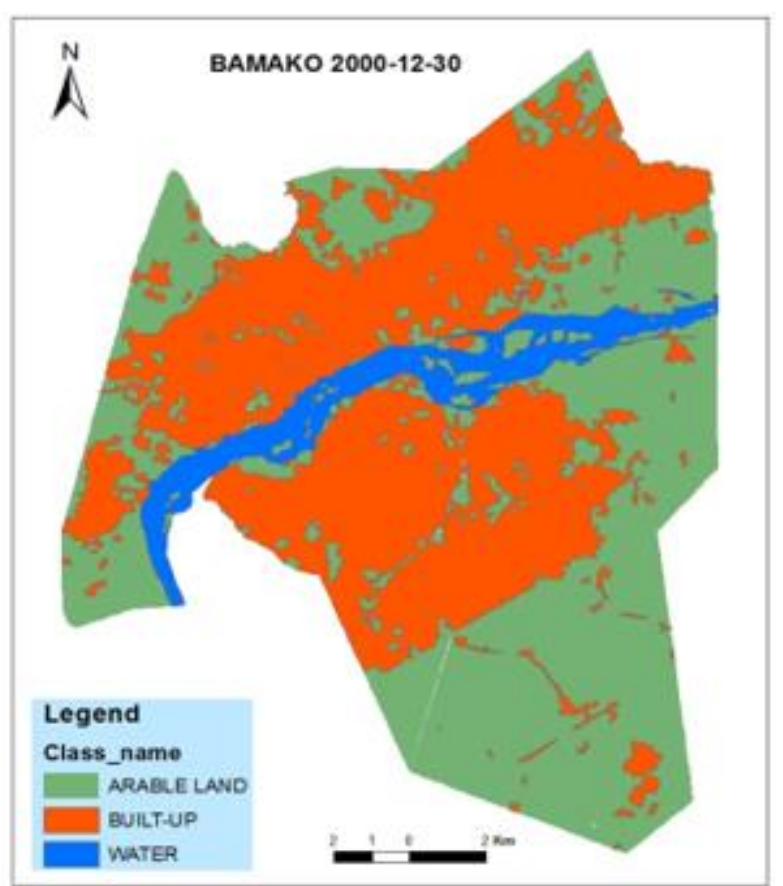

(b) 


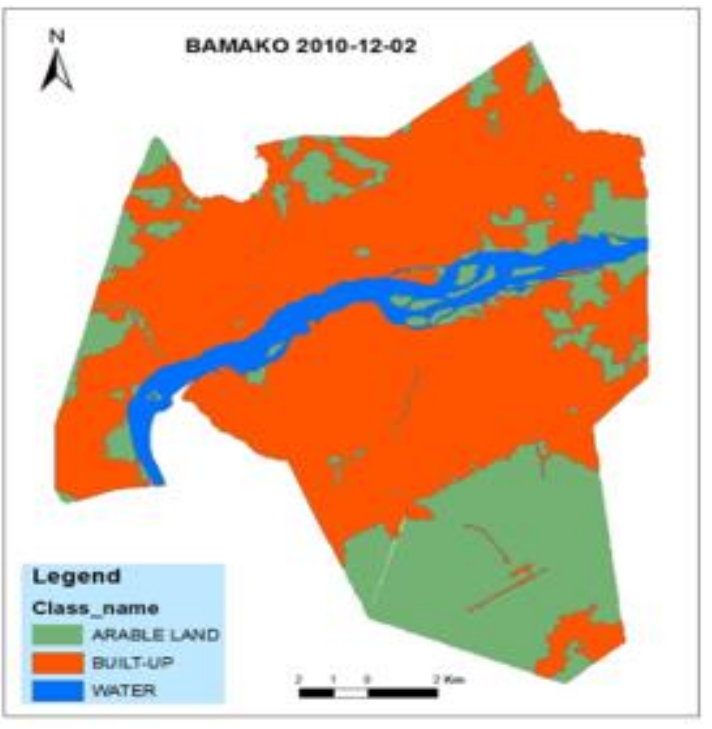

(c)

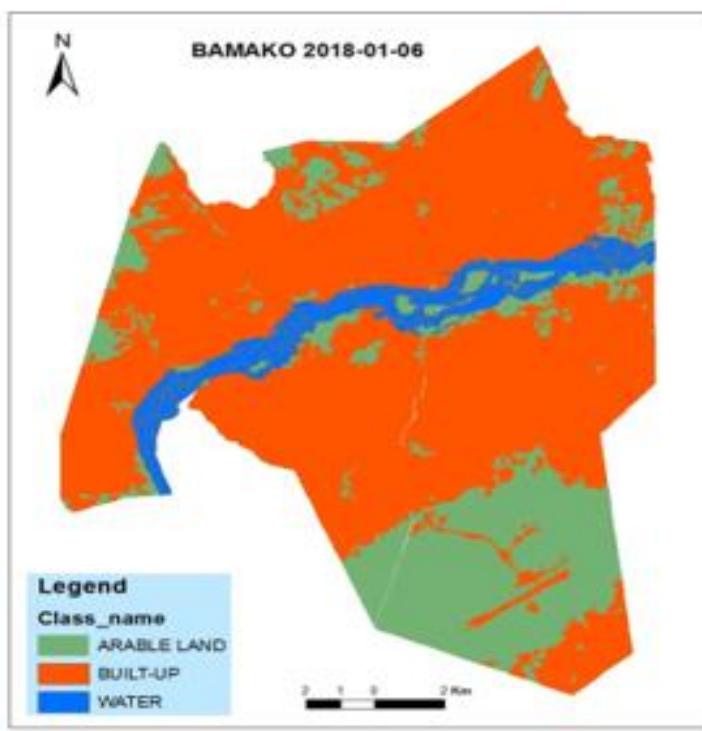

(d)

Figure 4: Mapping of urban sprawl in Bamako district: a (1990); b (2000); c (2010); d (2018)

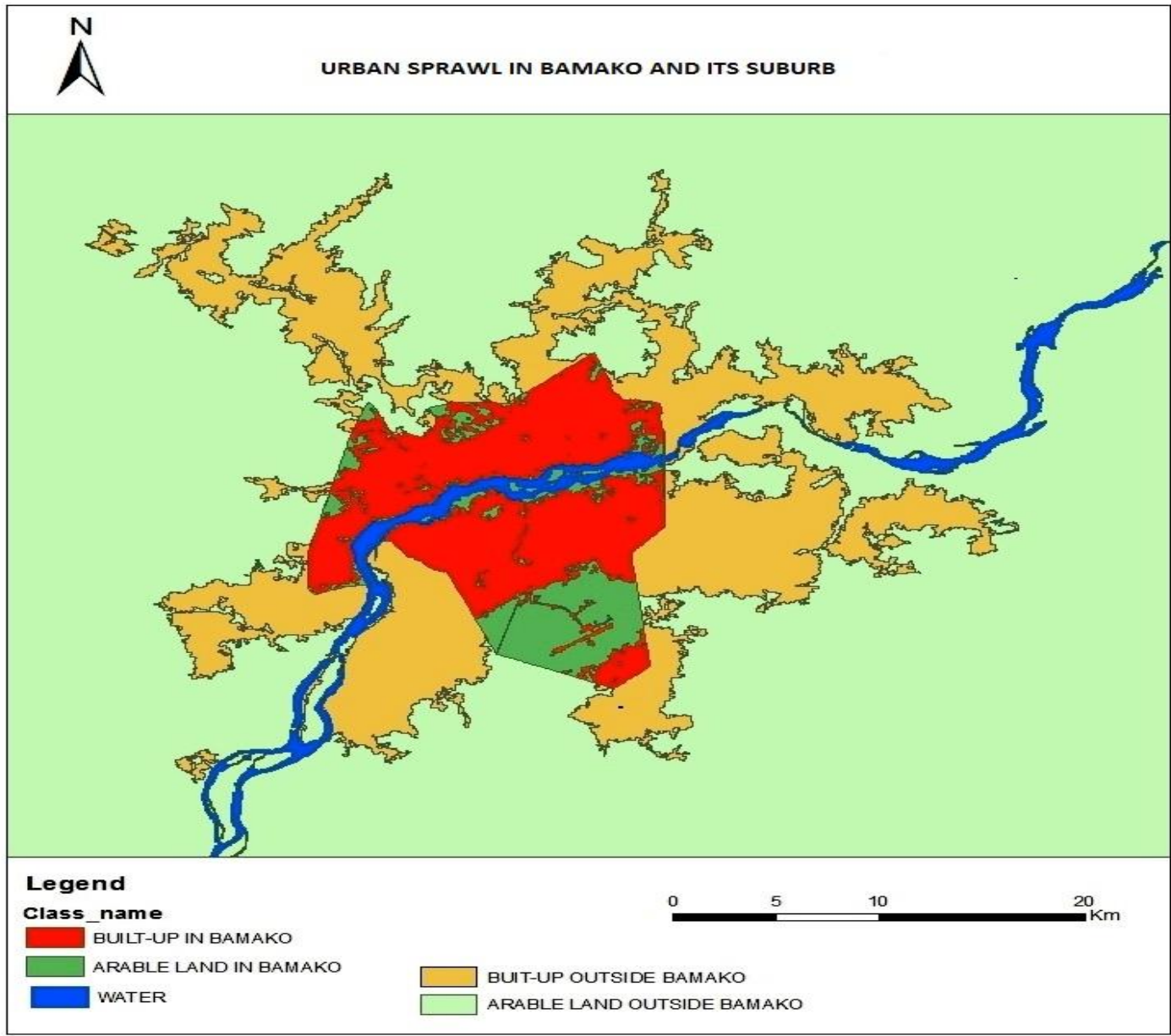

Figure 5: urban sprawl in Bamako and its suburb 
From Fig.5, it is clear that the built-up outside Bamako is so large as since the year 2000 urban sprawl is outside the boundaries of Bamako in neighboring municipalities. The only remaining green lands are arable land in the south part around the airport, and the mountain in the north part.

\subsection{Discussions}

The qualities of the results of this study are well enough to build up the phenomena of urban sprawl and arable land loss in Bamako district. However, it should be noted that it would be quite interesting to separate the mountainous areas from north to north-west by considering these as a class in order to extract them from arable land, even if a large part of the flanks and heights of these mountains are inhabited. The extraction of mountainous areas from arable land class could have allowed us to have more accurately the surfaces of arable land. A detailed analysis of arable land loss in each of Bamako's municipalities would make the study more meaningful by allowing a comparative analysis between municipalities during the study period. This study analyzed by municipalities could not be done due to the lack of availability of higher resolution quality satellite images, and lack of secondary data such as shape files of different municipalities of Bamako district. Another insufficiency of this study that can be a future prospect is that it does not provide the statistics of the spreading or the spatial evolution of the building and the arable lands outside the administrative limits of the district of Bamako knowing that since between 2000 and 2010 urban sprawl in this region has become more important in its peripheral communes and is still continuing at a high rate. The lack of these statistics should be understood on the one hand by the fact that the study was concerned only with the district of Bamako and on the other hand by the unavailability of secondary data such as the shapes files of the peripheral communes.

If it is concluded, according to the statistics of the study, that the period of greatest growth of the building and the period of greatest loss of arable land was between 2000 and 2010, then it should be emphasized that this would be dependent on administrative limits of Bamako district. It is inferred that during the same period, the urban sprawl of Bamako exceeded its administrative limits to continue in neighboring municipalities. In the neighboring administrative district of Kati, it bites a dozen of rural communes whose population growth often more than $12 \%$ per year, far exceeds that of the District [27]. It can be considered that a study taking into account the extension of Bamako District beyond its limits, and socio-ecological issues would give more interesting results to know.

\section{Conclusion and Recommendations}

Urban sprawl in Bamako has imposed a serious impact on arable land. It can be concluded that urban sprawl has almost covered all the arable land in the district of Bamako. Thus farmers are deprived of their land. The perfect example of Bamako is the degeneration of market gardeners along the rails, river borders, Sotuba and Hamdallaye ACI zones and others formerly dedicated to cereals. This is raising concerns of ecology and food security. Land use and land cover changes may have adverse impacts on ecology of the area, especially the greenness [28, 29, and 30]. Urban expansion is a double-edged sword. On one hand, it brings more convenience to human production and living while on the other hand; it has a lot of secondary problems such as environmental pollution [31]. Rapid urbanization to wildlife habitat, watershed lands, farmland and open spaces has many unintended consequences, including loss of key agricultural land, loss of natural 
resources, increased environmental pollution, congestion traffic and many other physical, social and economic effects [32, 33, 34]. Like other major cities in underdeveloped or developing countries, urban sprawl, which has become an issue for many rapidly developing sectors, refers to the uncontrolled growth of an urban area resulting from poorly or totally unplanned urbanization. The inability to visualize such growth during planning, policies and decision-making has led to sprawl that is both unsustainable and controversial [35]. At the Bamako Urbanization Forum in 2017, it has been argued that: In a space of time, the hoarding of space has finished destroying what nature had taken centuries to build. It has stopped destroying what our ancestors had the wisdom and the patience to plant, in order to safeguard, respect, by the duty of generation and for the balance of the ecological chain where everything is inter linked or interdependent. The hills, whose heights and arabesques made them natural masterpieces, are nowadays scarred, slashed and crushed by Space hunters.

The emergency measures must be taken to control urban sprawl and arable land loss. Legislative measures to protect agricultural land and intensification of agriculture in urban and peri-urban areas must be taken in promoting food security and sustainable development. Another measure could be the adoption of a vertical building policy and compact city model as in developed countries for conservation of farmland. To restrict the sprawling city from consuming prime arable lands, compact city model can be a way to go. Vertical building style should be adopted but cannot be achieved if relied on the individuals. This can be achieved with effective public-private partnership. It is argued that compact city structure will contribute in no mean way towards sustainable development of the city in terms of land use efficiency among other benefits [36, 37]. It is recommended to concretize the development of a management master plan for Bamako because this master plan was not available until 2017. Finally, territorial planning policy must give priority to the spatial distribution of infrastructure and socio-sanitary and economic services to the regional capitals. This policy could retain a maximum of migratory flow towards Bamako, as it is known that today, besides being the main center of economic activities of the country; almost $99 \%$ of universities are centered in Bamako. It should be noted that the levels and qualities of infrastructures and services are real factors of attractions and human concentrations in a given areas. The creation of a political capital towards the center of the country, such as Yamoussokro in Côte d'Ivoire and Brasilia in Brazil, with the transfer of several public institutions and the creation of socio-sanitary infrastructures generating jobs, would also be a better public policy of draining internal migrations towards this new pole; and would be an alternative to better control the urban sprawl of the district of Bamako as well as its urban area.

Government politics will be a key factor in controlling or encouraging sprawl, as was in the case of United States and China. The planning system and government policies are fundamental in encouraging or preventing urban sprawl. Taking the example of American, local governments are motivated to offer vacant land for commercial purposes to maximize the taxation generated by retailing [38]. The sale of the surrounding lands by countries, either for financial reasons or because of urban pressure on their land, contributes to urban sprawl or other motivations. County and village chiefs prefer to "sell" their land and annex their municipalities to the central city because peasants around the city center want to become "urban residents". This decentralized land use power thus contributes to urban sprawl [39]. 
Besides the ineffectiveness of laws or regulations enforcement, there are some other managerial factors leading to the urban sprawl, for instance, the leaders of some cities believe that urban land is more profitable than agricultural land, so they think that economic success is more likely to rely on urban land. This speeds up the rate of land conversion from cultivated land to urban land and promotes the urban sprawl. The loss of valuable agricultural land due to rapid urban growth has caught the attention of the central government [12]. One of the driving forces behind urban sprawl in the Bamako district and around uncontrolled land speculation involving formal and informal actors is the intention of state and local municipalities to better control the land market and prioritize lands before selling for maximum profit. The more land is developed, the more land lease revenue for the local government, the more profit for developers, and thus more opportunities for compensation for farmers.

Planning actors have been failed to apply long term planning principles. There is a need to change the underlying rules of the game so that environmental impacts of land conversion are fully taken into account in the future economic calculations [40]. The spatial extension of Bamako, just like most capital cities in Africa, has not received as much attention as its population growth. This extension, sustained by an acute crisis of housing and increased land speculation, seems nevertheless worrying because of the various problems that it creates: difficulties of development, equipment, housing etc. The extension is more disturbing as it seems to take place outside the programming of the master plan of urban development [41].

\section{Acknowledgements}

This work was supported by the Key R \& D Program of Jiangsu Province [No. BE2017115].

\section{References}

[1] Manirakiza, vincent, (2011), processus d'urbanisation de la ville de kigali, rwanda : relation entre la dynamique spatiale et demographique (urbanization process of the city of kigali, rwanda : relationship between spatial and demographic dynamics), communication pour la chaire quetelet 2011 « urbanisation, migrations internes et comportements démographiques

[2] Transportation research board, (2002). Costs of sprawl 2000, in: transit cooperative research program report 74, national academy press, washington, dc, s. 88

[3] jiang fang, liu shenghe, yuan hong and zhang qing, 2007, measuring urban sprawl in beijing with geo-spatial indices, journal of geographical science, 17,4: $469-478$.

[4] United nations. World urbanization prospects: the 2011 revision data tables and highlights. New york: united nations; 2012.

[5] Cohen barney, 2006. Urbanization in developing countries: current trends, future projections, and key challenges for sustainability. Technology in society 28 63-80

[6] Abass kabila, adanu, selase koffi, agyemang seth, 2018. Peri-urbanisation and loss of arable land in kumasi metropolis in three decades: evidence from remote sensing image analysis, land use policy 72 (2018) 470-479

[7] Wolch jennifer $r$, byrne jason, and newell joshua p., 2014, urban green space, public health and environmental justice: the challenge of making cities 'just green enough', landscape and urban planning 125 (2017) $2034-244$.

[8] Diarra balla., 2015, croissance demographique et modes d'insertion des populations dans le tissu urbain de bamako (demographic growth and population insertion methods in the fabric in bamako), revue de géographie tropicale et d'environnement, $\mathrm{n}^{\circ} 2,2015$ 
[9] Xiao jieying, shen yanjun, ge jingfeng, et al. 2005, evaluating urban expansion and land use change in shijiazhuang,china, by using gis and remote sensing, landscape and urban planning 75 (2006) 69-80

[10] Delcourt laurent. (ed.). (2007). Explosion urbaine et mondialisation. Points de vue du sud (urban explosion and globalization. Southern viewpoints), louvainla-neuve / paris, centre tricontinental / editions syllepse.

[11] Chorianopoulos ioannis, pagonis thomas and drymoniti semeli. (2010), planning, competitiveness and sprawl in the mediterranean cities: the case of athens, cities, 27, 4, $249-259$

[12] Deng xiangzheng, zhan jiyan and chen rui, 2005. The patterns and driving forces of urban sprawl in china, ieee, 0-7803-9050-4/05/\$20.00 @2005 ieee.

[13] Grubler, arnulf, (1994), technology. In: william b. Meyer and b.l. turner ii (editors), changes in land use and land cover: a global perspective. Cambridge university press, cambridge, u.k.

[14] Li feng 2012, investigation of urban sprawl on the basis of remote sensing data: a case study in jiangning, nanjing city, china, phd thesis, university of stuttgart

[15] Naab francis zana, dinye ramanus dogkubong and kasanga raphael kassim, 2013, urbanisation and its impact on agricultural lands in growing cities in developing countries: a case study of tamale in ghana, modern social science journal, 2(2013), 256 - 287

[16] Diallo boubacar amadou and zhengyu bao., 2010, land cover change assessment using remote sensing: case study of bamako, mali. Researcher, 2 (4), 7-17

[17] Carlson tobi n., traci arthur s., 2000. The impact of land use-land cover changes due to urbanization on surface microclimate and hydrology: a satellite perspective. Global planetary change 25, 49-65.

[18] Aguilar adrian g., ward peter m. And smith sr c.b., 2003. Globalization, regional development, and mega-city expansion in latin america: analyzing mexico city's peri-urban hinterland. Cities $20,3-$ 21.

[19] Schneider annemarie, 2012, monitoring land cover change in urban and peri-urban areas using dense time stacks of landsat satellite data and a data mining approach, remote sensing of environment 124 (2012) 689-704

[20] Lu shan, lu xingtong, zhao wenli, liu yu, wang zheyi and omasa kendi, 2015. Comparing vegetation indices for remote chlorophyll measurement of white poplar and chinese elm leaves with different adaxial and abaxial surfaces. J. Exp. Bot. 66 (18), 5625-5637.

[21] Definiens imaging, (2004).ecognition professional, user guide 4.0.germany, 486p.

[22] Hoang kim hong, bernier monique and villeneuve jean pierre, (2007), les changements de l'occupation du sol et ses impacts sur les eaux de surface du bassin versant de la riviere de cau (vietnam), changes in land use and its impacts on surface waters of the cau river watershed (vietnam), actes des jsirauf, hanoi, 6-9 novembre

[23] Congalton russel g., 1991. A review of assessing the accuracy of classifications of remotely sensed data. Remote sens. Environ. 37 (1), 35-46.

[24] Story michael, congalton russel g., 1986. Accuracy assessment: a user's perspective. Photogramm. Eng. Remote sens. 52 (3), 397-399.

[25] Bamako district municipality, 2001, local governance, poverty and partnership in bamako district (gouvernance locale, pauvreté et parténariat dans le district de bamko), report volume 1. P 162

[26] Corubolo enrico, mattingly michael, 1999, 'peri-urban profiles.kumasi (ghana)' (development planning unit working paper). University college london, london.

[27] Bertrand monique, 2015, the urban area of bamako: the search for a local political consensus for a united project, géocarrefour, 90, $93-49$

[28] [28] herold martin, goldstein noah c. And clarke keith c, 2003. The spatiotemporal form of urban growth: measurement, analysis and modeling. Remote sens. Environ., 86: 286-302.

[29] Liu xiaohang and lathrop jr richard g, 2002. Urban change detection based on an artificial neural network. Int. J. Remote sens., 23: 2513-2518.

[30] Grimm nancy b., grove j. Grove, pickett steward a.t. and redman charles 1., 2000. Integrated approaches to long-term studies of urban ecological systems: urban ecological systems present 
multiple challenges to ecologists-pervasive human impact and extreme heterogeneity of cities and the need to integrate social and ecological approaches, concepts and theory. Bioscience, 50: 571584.

[31] Zhang junfeng, mauzerall denise 1., zhu tong et al, 2010, environmental health in china: progress towards clean air and safe water. Lancet, 2010, 375: 1110-1119

[32] Burchell, robert w. And shad naveed. A., (1999), the evolution of the sprawl debate in the united states. West-northwest journal of environmental law \& policy, 5: 137-160

[33] Ewing reid, (1997), is los angeles-style sprawl desirable? Journal of the american planning association 63 107-26

[34] Hasse john, and lathrop richard g, (2003), a housing-unit-level to characterizing residential sprawl, photogrammetric engineering and remote sensing 69: 1021-30

[35] Noor, n.m., asmawi m.z. and rusni n.a., (2014), iop conf. Ser.: earth environ. Sci. 18012174 ; doi:10.1088/1755-1315/18/1/012174

[36] Camagni roberto, gibelli maria cristina, rigamonti paolo, 2002. Urban mobility and urban form: the social and environmental costs of different patterns of urban expansion. Ecol. Econ. 40 (2), 199216.

[37] Thinh nguyen xuan, arlt günter, heber bernd et al, 2002. Evaluation of urban land-use structure with a view to sustainable development. Environ. Impact assess. Rev. 22 (5), 475-492

[38] Jiang xiaolei, (2009), urban form for china's larger cities-the example of beijing municipality, in: master thesis, blekinge institute of technology.

[39] Zhang tingwei, (2000). Land market forces and government's role in sprawl: the case of china. Cities, 17, 123-135.

[40] Fang yiping and pal anirban, 2016, drivers of urban sprawl in urbanizing china - a political ecology analysis, international institute for environment and development (iied), vol 28(2): 599616. Doi: 10.1177/0956247816647344 www.sagepublications.com

[41] Diarra balla., ballo m.oïse and champaud jacques. 2003, structure urbaine et dynamique spatiale a bamako (urban structure and spatial dynamic in bamako), edition donnya, bamako

*Corresponding author.

E-mail address: rrz@ hhu.edu.cn 